\title{
Pendidikan Kesehatan Cuci Tangan Pakai Sabun dengan Video Terhadap Kemampuan Cuci Tangan pada Siswa SD
}

\author{
Ni Ketut Vera Parasyanti ${ }^{1}$, Ni Luh Gede Puspita Yanti ${ }^{2}$, I Gusti Agung Ayu Putri Mastini ${ }^{3}$ \\ Sekolah Tinggi Ilmu Kesehatan Wira Medika Bali ${ }^{1,2,3}$ \\ Email:Veraparasyanti62@gmail.com
}

Submitted : 06/02/2020

Accepted: $15 / 02 / 2020$

Published: $14 / 03 / 2020$

\begin{abstract}
Introduction: The problem that often happens to the school kids is related to hygiene and environment, one of them is washing off the hands with soap (CTPS). The prevalence of washing hands behavior is an increase from 47,0\% to 49,8\%. This research aims to analyze the impact of CTPS health education with video as the media toward the capability of washing the hands on the $3^{\text {rd }}$-grade students. Method: The pre-experimental design method with one group pretest design approach is used. The sample consists of 27 students who are chosen by the total sampling technique. Result : Before being given the CTPS health education, there are 24 children $(88,9 \%)$ in the category of incapable to do the steps of CTPS, and there are 3 children $(11,1 \%)$ in the category of capable to do it. After being given the CTPS health education, 25 children (92,6\%) are in the capable category and 2 children $(7,4 \%)$ are in the incapable category. Based on the result of Wilcoxon Sign Rank Test, it's known that p-value $=0,000$ with $(a<0,05)$, it means that there is an impact from the health education of washing hands with soap by video as the media toward the capability of washing the hands on the $3^{\text {rd }}$ student at Elementary School Number 1 Berangbang, Jembrana. Discussion : Based on that result, a CTPS health education by video as the media is recommended to increase the capability of washing the hands to the school kids.
\end{abstract}

Keywords: elementary school student, video, washing hands

\begin{abstract}
Abstrak
Pendahuluan : Permasalahan yang sering terjadi pada anak usia sekolah biasanya selalu berkaitan dengan kebersihan dan lingkungan salah satunya adalah cuci tangan pakai sabun (CTPS). Prevalensi perilaku mencuci tangan dengan benar di Indonesia terjadi peningkatan dari 47,0\% menjadi 49,8\%. Penelitian ini bertujuan untuk menganalisis pengaruh pendidikan kesehatan CTPS dengan media video terhadap kemampuan cuci tangan pada siswa kelas III. Metode : Penelitian ini menggunakan metode pre eksperimental design dengan pendekatan one group pretest posttest design. Sampel terdiri dari 27 siswa yang dipilih dengan teknik total sampling. Hasil : Sebelum diberikan pendidikan kesehatan CTPS, 24 anak $(88,9 \%)$ dalam kategori tidak mampu melakukan langkah CTPS, dan 3 anak $(11,1 \%)$ dalam kategori mampu. Setelah diberikan pendidikan kesehatan CTPS 25 anak (92,6\%) dalam kategori mampu, 2 anak $(7,4 \%)$ dalam kategori tidak mampu. Hasil uji Wilcoxon Sign Rank Test diketahui $p$ value $=0,000$ dengan $(\alpha<0,05)$, berarti ada pengaruh pendidikan kesehatan cuci tangan pakai sabun dengan media video terhadap kemampuan cuci tangan pada siswa kelas III SDN 1 Berangbang Jembrana. Diskusi : Berdasarkan hasil tersebut disarankan agar ada pendididkan kesehatan CTPS dengan media video untuk meningkatkan kemampuan cuci tangan anak usia sekolah.
\end{abstract}

Kata kunci : cuci tangan, siswa SD, video

\section{PENDAHULUAN}

Kesehatan merupakan hal penting dalam hidup manusia. Derajat kesehatan yang optimal dapat dicapai dengan adanya penerapan PHBS (Perilaku Hidup Bersih dan Sehat). Pelaksanaan program PHBS dikelompokkan menjadi 5 tatanan, salah satunya pada istitusi pendidikan yaitu di sekolah (Depkes RI, 2011). PHBS di sekolah perlu mendapatkan perhatian dimana anak usia sekolah khususnya tingkat sekolah dasar (6-12 tahun) 
merupakan masa anak rentan terhadap berbagai penyakit, yang umumnya ternyata berkaitan dengan perilaku hidup bersih dan sehat. Salah satu indikator penting dari pelaksanaan PHBS di sekolah dapat dimulai dari hal yang sederhana yaitu mencuci tangan pakai sabun. Cuci tangan pakai sabun adalah proses membuang kotoran dan debu secara mekanis dari permukaan kulit, kuku, jari jemari pada kedua tangan dengan menggunakan sabun dan air mengalir untuk mengurangi jumlah mikroorganisme penyebab penyakit (Dahlan \& Umrah, 2013).

Menurut Public-Private Partnership for Handwashing with Soap (PPPHWS) dalam UNICEF (2008) menunjukkan bahwa hanya $10 \%$ orang yang mencuci tangan dengan menggunakan sabun. Berdasarkan Data Riset Kesehatan Dasar Tahun 2018, proporsi penduduk umur kurang dari 10 tahun yang berperilaku cuci tangan dengan benar di Indonesia telah meningkat dari $47,0 \%$ pada tahun 2013 menjadi $49,8 \%$ pada tahun 2018. Provinsi Bali merupakan hasil tertinggi dari provinsi yang lain yang ada di Indonesia, dimana proporsi penduduk umur kurang dari 10 tahun yang berperilaku cuci tangan dengan benar yaitu $62,71 \%$ pada tahun 2015 menjadi $67,4 \%$ pada tahun 2018 dari target $82 \%$. Menurut data PHBS Provinsi Bali tahun 2015, menyebutkan bahwa Sekolah yang PHBSnya terendah yaitu Tabanan dengan cakupan PHBS yaitu 60,82\%, kedua Karangasem 72,09\%, ketiga Bangli $73,11 \%$, keempat Buleleng 74,03\%, kelima Gianyar $78,10 \%$, keenam yaitu di Jembrana 79,07\%, ketujuh Badung 80,16\%, kedelapan Kota Denpasar 81,48\% dan kesembilan Klungkung 81,80\% (Dinkes Provinsi Bali, 2015). Menurut data Profil Promosi Kesehatan Puskesmas 1 Negara (2017), wilayah kerja Puskesmas 1 Negara yaitu terdapat 6 Desa, dimana Desa Berangbang merupakan prosentase terendah yang berperilaku hidup bersih dan sehat yaitu sebesar $70 \%$.
Dampak yang dapat terjadi akibat tidak mencuci tangan pakai sabun dengan benar yaitu seperti penyakit Diare dan ISPA (Infeksi Saluran Pernapasan Atas) yang sering menjadi penyebab kematian pada anak-anak, dan juga penyakit Hepatitis, Thypus dan Flu Burung (Kemenkes RI, 2015). Diare merupakan penyakit endemis di Indonesia dan merupakan penyakit potensial Kejadian Luar Biasa (KLB) yang sering disertai dengan kematian. Menurut WHO (2013), setiap tahun rata-rata 100 ribu anak meninggal dunia karena Diare. Data dari Subdit diare Kemenkes juga menunjukkan sekitar 300 orang di antara 1000 penduduk masih terjangkit diare sepanjang tahun (Profil Kesehatan Indonesia Tahun 2013). Penyebab dari semua kematian anak akibat diare, dimana $78 \%$ khususnya di Indonesia dikarenakan buruknya perilaku hygiene perorangan dan sanitasi masyarakat (Evayanti, 2014). Penyakit saluran pencernaan salah satunya diare juga masih cukup tinggi ditemukan di Provinsi Bali. Jumlah penemuan kasus pada tahun 2018 sekitar 68.142 orang (Profil Kesehatan Tahun 2018). Berdasarkan data Dinas Kesehatan Kabupaten Jembrana, pada tahun 2018 jumlah penemuan kasus diare pada anak masih tinggi yaitu 4.845 kasus (Dinkes Kabupaten Jembrana, 2018).

Upaya yang sudah dilakukan WHO untuk mengatasi masalah kurangnya kesadaran untuk cuci tangan salah satunya adalah memperingati Hari Cuci Tangan Pakai Sabun (HCTPS) pada tanggal 15 Oktober yang merupakan upaya untuk meningkatkan budaya CTPS secara global. Pada tatanan sekolah, salah satu yang dapat dilakukan untuk meningkatkan kemampuan anak mengenai mencuci tangan pakai sabun yaitu dengan memberikan pendidikan kesehatan. Anak usia sekolah juga merupakan masa keemasan untuk menanamkan nilai-nilai PHBS dan berpotensi sebagai agent of change untuk mempromosikan PHBS baik di lingkungan sekolah, keluarga, maupun masyarakat 
karena pada taraf ini anak sangat peka terhadap stimulus sehingga mudah dibimbing, diarahkan dan ditanamkan kebiasaan-kebiasaan yang baik karena anak berada pada taraf pertumbuhan dan perkembangan (Linda dan Adiwiryono, 2010).

Pada usia anak-anak untuk menyampaikan pesan membutuhkan media yang tepat karena anak suka berimajinasi, salah satu media yang tepat yaitu media audiovisual atau video (Prastowo, 2012). Media video dapat lebih mudah untuk dimengerti siswa. Penggunaan media video akan mampu mencapai efektivitas proses pembelajaran, mengarahkan perhatian anak untuk berkonsentrasi pada materi yang dipelajari sehingga poses pembelajaran menjadi menarik dan video juga dapat menggambarkan suatu proses secara tepat dan dapat dilihat secara berulang-ulang (Arsyad, 2011).

Berdasarkan hasil studi pendahuluan yang dilakukan pada tanggal 15 Juli 2019 di SDN 1 Berangbang Jembrana yaitu kurangnya fasilitas yang tersedia untuk mencuci tangan dimana hanya tersedia satu waskom di depan kelas masing-masing dan tidak tersedianya wastafel dan sabun untuk cuci tangan akibat aliran air yang tidak lancar khususnya. Hasil wawancara yang dilakukan terhadap Kepala Sekolah SDN 1 Berangbang Jembrana yaitu sebagian besar siswa di SD melakukan cuci tangan sebelum dan sesudah makan dan juga apabila tangan dalam keadaan kotor, namun belum menggunakan langkah-langkah cuci tangan dengan benar dikarenakan kurangnya pengetahuan tentang teknik cuci tangan. Kepala Sekolah juga mengatakan dari tim kesehatan sudah pernah memberikan pendidikan kesehatan tentang cuci tangan terakhir pada satu tahun yang lalu, namun itu baru diberikan pada siswa kelas IV, V, dan VI saja. Hasil observasi terhadap siswa kelas III SD dalam mencuci tangan saat istirahat, sebanyak 12 orang siswa mencuci tangan menggunakan satu waskom secara bersama-sama dan tidak menggunakan teknik mencuci tangan dengan benar, sedangkan sebanyak 15 orang tidak mencuci tangan sesaat sebelum makan.

Berdasarkan dari uraian di atas, maka peneliti tertarik untuk mengangkat judul penelitian tentang Pengaruh Pendidikan Kesehatan Cuci Tangan Pakai Sabun dengan Media Video Terhadap Kemampuan Cuci Tangan Pada Siswa Kelas III SDN 1 Berangbang Jembrana.

\section{METODE PENELITIAN}

Desain penelitian yang digunakan dalam penelitian ini adalah pre eksperimental design. Rancangan dalam penelitian ini menggunakan one group pretest posttest design. Pada penelitian ini pengukuran perilaku mencuci tangan

dilakukan sebanyak dua kali yaitu sebelum perlakuan (pretest) dan sesudah perlakuan (posttest). Intervensi diberikan 2 kali seminggu berlangsung dalam 2 minggu. Populasi pada penelitian ini adalah siswa kelas III di SDN 1 Berangbang berjumlah 27 orang siswa. Sampel dalam penelitian ini adalah 27 orang. Pengambilan sampel menggunakan teknik non probably sampling jenis total sampling atau sampel jenuh karena jumlah sampel kurang dari 100 sehingga jumlah sampel sama dengan populasi. Pengambilan data dilaksanakan di SDN 1 Berangbang Jembrana pada tanggal 21 Oktober 2019 - 2 November 2019. Penelitian menggunakan instrumen penelitian berupa Standar Operasional Prosedur (SOP) dan lembar observasi cuci tangan yang sudah ditetapkan. Teknik analisa data yang digunakan untuk menguji pengaruh dalam penelitian ini adalah uji Wilcoxon Signed Rank Test (nilai probabilitas $\mathrm{p} \leq 0,05)$.

\section{HASIL DAN PEMBAHASAN}

Hasil penelitian pada pembahasan akan diawali dengan hasil intepretasi data diskusi hasil penelitian. Pembahasan 
meliputi kemampuan cuci tangan siswa kelas III sebelum dan sesudah diberikan pendidikan kesehatan cuci tangan dengan media video serta analisa pengaruh pendidikan kesehatan cuci tangan pakai sabun dengan media video terhadap kemampuan cuci tangan.

\section{Hasil}

Tabel 1.

Karakteristik Responden Berdasarkan Jenis Kelamin

\begin{tabular}{|c|c|c|}
\hline $\begin{array}{c}\text { Jenis } \\
\text { Kelamin }\end{array}$ & $\begin{array}{c}\text { Jumlah } \\
\text { (anak) }\end{array}$ & $\begin{array}{c}\text { Presentase } \\
(\%)\end{array}$ \\
\hline Laki-laki & 12 & 44,4 \\
\hline $\begin{array}{c}\text { Perempua } \\
n\end{array}$ & 15 & 55,6 \\
\hline Total & 27 & 100,0 \\
\hline
\end{tabular}

bahwa sebagian besar jenis kelamin responden adalah perempuan yaitu sebanyak 15 responden $(55,6 \%)$.

Tabel 2. Distribusi Frekuensi Kemampuan Cuci Tangan Sebelum Diberikan Pendidikan Kesehatan

\begin{tabular}{ccc}
\hline $\begin{array}{c}\text { Kategori } \\
\text { Kemampuan } \\
\text { Cuci Tangan }\end{array}$ & $\begin{array}{c}\text { Jumlah } \\
\text { (anak) }\end{array}$ & $\begin{array}{c}\text { Persen } \\
\text { tase } \\
(\%)\end{array}$ \\
\hline Laki-laki & 1 & 3.7 \\
\hline Mampu & 11 & 40.8 \\
\hline $\begin{array}{c}\text { Tidak } \\
\text { mampu }\end{array}$ & 11 & 7.4 \\
\hline Perempuan & & 48.1 \\
\hline Mampu & 2 & 100
\end{tabular}

Tabel 2 menunjukkan hasil pengamatan awal saat dilakukan pretest didapatkan hasil bahwa bahwa sebagian besar kemampuan cuci tangan dari 27 responden sebanyak 24 anak $(88,9 \%)$ dikategorikan tidak mampu melakukan langkah cuci tangan dengan benar, dan 3 anak $(11,1 \%)$ dikategorikan mampu melakukan langkah cuci tangan sesuai SPO cuci tangan.
Tabel 3. Distribusi Frekuensi Kemampuan Cuci Tangan Sesudah Diberikan Pendidikan Kesehatan

\begin{tabular}{ccc}
\hline $\begin{array}{c}\text { Kategori } \\
\text { Kemampuan } \\
\text { Cuci Tangan }\end{array}$ & $\begin{array}{c}\text { Jumlah } \\
\text { (anak) }\end{array}$ & $\begin{array}{c}\text { Persenta } \\
\text { se }(\%)\end{array}$ \\
\hline Laki-laki & 10 & 37 \\
\hline Mampu & 2 & 7.4 \\
\hline $\begin{array}{c}\text { Tidak } \\
\text { mampu }\end{array}$ & 15 & 55.6 \\
\hline Perempuan & 0 & 0 \\
\hline Mampu & 15 \\
\hline $\begin{array}{c}\text { Tidak } \\
\text { mampu }\end{array}$ & 0 & 100 \\
\hline Total diatas
\end{tabular}

menunjukkan bahwa sebagian besar dari responden sebanyak 25 siswa $(92,6 \%)$ dalam kategori mampu dan sebanyak 2 siswa $(7,4 \%)$ dalam kategori tidak mampu dalam mencuci tangan setelah diberikan pendidikan kesehatan cuci tangan pakai sabun dengan media video.

Tabel 4. Pengaruh pendidikan kesehatan cuci tangan pakai sabun dengan media video terhadap kemampuan cuci tangan

\begin{tabular}{cccccc}
\hline Kategori & \multicolumn{2}{c}{ Hasil } & \multicolumn{2}{c}{ Hasil } & \\
Kemampuan & Pretest & \multicolumn{2}{c}{ Posttest } & $p$ \\
\cline { 2 - 5 } Cuci Tangan & $\mathrm{F}$ & $(\%)$ & $\mathrm{F}$ & $(\%)$ & \\
\hline Mampu & 3 & 11,1 & 2 & 92,6 & 0.00 \\
Tidak Mampu & 24 & 88,9 & 2 & 7,4 & \\
\hline Total & 27 & 100 & 2 & 100 & \\
\hline Hasil analisa data mengounakan uji
\end{tabular}
Wilcoxon Signed Rank Test diperoleh nilai Asymp. Sig.(2-tailed) sebesar 0.000 yang memiliki nilai lebih kecil dari nilai signifikan yaitu $\alpha$ ( $p$ value $<\alpha, \alpha=0,05)$ sehingga $\mathrm{HO}$ ditolak dan Ha diterima yang menunjukkan pengaruh yang signifikan. Maka, dapat diartikan bahwa ada pengaruh pendidikan kesehatan cuci tangan pakai sabun dengan media video terhadap kemampuan pada siswa kelas III. Ada perubahan kemapuan cuci tangan sebelum 
dan setelah diberikan pendidikan kesehatan cuci tangan pakai sabun dengan media video. Terjadi peningkatan pada kategori mampu yaitu dari $11,1 \%$ menjadi $92,6 \%$ sedangkan terjadi penurunan pada kategori tidak mampu dari $89,9 \%$ menjadi $7,4 \%$.

Hasil analisa data menggunakan uji Wilcoxon Signed Rank Test diperoleh nilai Asymp. Sig.

(2-tailed) sebesar 0.000 yang memiliki nilai lebih kecil dari nilai signifikan yaitu $\alpha$ (p value $<\alpha, \alpha=0,05$ ) sehingga $\mathrm{H} 0$ ditolak dan Ha diterima yang menunjukkan pengaruh yang signifikan. Maka, dapat diartikan bahwa ada pengaruh pendidikan kesehatan cuci tangan pakai sabun dengan media video terhadap kemampuan pada siswa kelas III. Ada perubahan kemapuan cuci tangan sebelum dan setelah diberikan pendidikan kesehatan cuci tangan pakai sabun dengan media video. Terjadi peningkatan pada kategori mampu yaitu dari $11,1 \%$ menjadi $92,6 \%$ sedangkan terjadi penurunan pada kategori tidak mampu dari $89,9 \%$ menjadi $7,4 \%$.

\section{Pembahasan}

a. Kemampuan cuci tangan sebelum diberikan pendidikan kesehatan cuci tangan pakai sabun dengan media video

Hasil penelitian sebelum mendapatkan pendidikan kesehatan dengan media video sebagian besar responden diketahui memiliki kemampuan cuci tangan pada kategori tidak mampu. Hasil penelitian ini juga sejalan dengan hasil penelitian sebelumnya yang dilakukan oleh Andriani (2017), yang menyatakan bahwa sebelum mendapatkan pendidikan kesehatan mencuci tangan sebagian besar responden berkemampuan kurang $(65,6 \%)$ dalam mencuci tangan pakai sabun.

Menurut Kushartanti (2012) dalam Kusbiantoro (2015) yang menjelaskan bahwa ada tiga faktor yang mempengaruhi kemampuan anak untuk mencuci tangan pakai sabun yaitu host (contohnya seperti :umur, jenis kelamin, tingkat pendidikan, dan motivasi), environment (contohnya seperti : lingkungan fisik, lingkungan sosial, sarana kesehatan), dan agent (gaya hidup dari penggunaan sabun dalam mencuci tangan, peraturan sekolah, pola asuh orang tua, ketersediaan media pendidikan, informasi dan keberadaan UKS).

Faktor internal dan eksternal pada individu anak memiliki pengaruh yang penting terhadap kemampuan cuci tangan pakai sabun dengan benar. Kurangnya fasilitas yang tersedia untuk mencuci tangan di sekolah dan kurangnya pendidikan kesehatan yang diberikan oleh guru maupun petugas kesehatan, maka anak-anak tidak mendapatkan pengetahuan yang lengkap mengenai pentingnya mencuci tangan pakai sabun dengan teknik yang benar sehingga anak-anak kurang antusias untuk mencuci tangan pakai sabun dan masih banyak ditemukan anak yang tidak mampu melakukan teknik mencuci tangan pakai sabun yang benar.

\section{b. Kemampuan cuci tangan setelah diberikan pendidikan kesehatan cuci tangan pakai sabun dengan media video}

Hasil penelitian setelah diberikan pendidikan kesehatan cuci tangan pakai sabun dengan media video menunjukkan bahwa sebagian besar dari responden dalam kategori mampu. Hasil penelitian ini sejalan dengan penelitian yang dilakukan oleh Sasmitha (2017), yang menyatakan bahwa setelah diberikan pendidikan kesehatan cuci tangan dengan media video sebagian besar dari 21 responden sebanyak 17 responden $(81,0 \%)$ yang memiliki pengetahuan baik tentang cuci tangan. Hasil penelitian ini juga didukung oleh 
penelitian yang dilakukan oleh Wati, dkk (2017), diperoleh hasil bahwa ada pengaruh pendidikan kesehatan dengan media audiovisual terhadap pengetahuan tentang cuci tangan pada anak usia sekolah.

Menurut Effendy (2012), pendidikan kesehatan bertujuan mengubah perilaku kurang sehat menjadi sehat yang artinya dapat mengubah pengetahuan responden yang kurang baik menjadi baik. Pada usia anak-anak untuk menyampaikan pesan membutuhkan media yang tepat karena anak suka berimajinasi, salah satu media yang tepat yaitu media audiovisual atau video (Prastowo, 2012). Menyampaikan pesan dengan menggunakan video lebih menarik perhatian dan motivasi bagi penonton. Pesan yang disampaikan lebih efisien karena gambar bergerak dapat mengkomunikasikan pesan dengan cepat dan nyata. Oleh karena itu, dapat mempercepat pemahamam pesan secara lebih komperehensif. Pesan audiovisual juga lebih efektif karena penyajiannya membuat penonton lebih berkonsentrasi (Lufianti, 2010).

c. Analisa pengaruh pendidikan kesehatan cuci tangan pakai sabun dengan media video terhadap kemampuan cuci tangan

Berdasarkan tabel 4. hasil penelitian sebelum dan setelah pemberian pendidikan kesehatan cuci tangan pakai sabun dengan media video terjadi perubahan yang singnifikan sesuai dengan prosedur. Penelitian dari Saputri \& Suryati (2019), dapat menguatkan penelitian ini karena terbukti dengan menerapkan media audiovisual pada anak kelas IV di MI Jamilurrahman Bantul dapat meningkatkan pengetahuan cuci tangan pakai sabun pada anak. Hal ini menyatakan bahwa dengan video pesan yang disampaikan lebih menarik perhatian dan motivasi penonton. Ardianto (2013) dalam penelitiannya mengatakan bahwa media audiovisual memiliki keunggulan karena menyampaikan pengertian dan informasi dengan cara yang lebih konkrit atau lebih nyata daripada yang dapat disampaikan oleh kata-kata yang diucapkan, sehingga anak antusias terhadap video yang diberikan tentang cuci tangan dan dapat mempengaruhi pengetahuan anak tersebut.

Salah satu faktor yang mempengaruhi kemampuan anak dalam cuci tangan pakai sabun yaitu jenis kelamin. Berdasarkan tabel 2 dan 3 menunjukkan bahwa sebelum diberikan pendidikan kesehatan cuci tangan pakai sabun, dari 15 anak perempuan didapatkan 13 anak (86,7\%) dalam kategori tidak mampu melakukan cuci tangan dengan benar, sedangkan dari 12 anak laki-laki didapatkan 11 anak $(97,7 \%)$ dalam kategori tidak mampu melakukan cuci tangan dengan benar. Setelah diberikan pendidikan kesehatan cuci tangan pakai sabun, didapatkan 15 anak perempuan $(100 \%)$ dalam kategori mampu melakukan cuci tangan dengan benar dan 10 anak laki-laki (83,3\%) dalam kategori mampu melakukan cuci tangan dengan benar. Penelitian ini sejalan dengan penelitian yang dilakukan oleh Andriani (2017), didapatkan hasil bahwa sebelum diberikan pendidikan kesehatan cuci tangan dengan media audiovisual, dari 19 anak perempuan didapatkan 12 anak berkemampuan kurang dan 7 anak berkemampuan cukup, sedangkan dari 13 anak laki-laki didapatkan 9 anak berkemampuan kurang dan 4 anak berkemampuan cukup. Setelah ditampilkan media audio visual, dari 19 anak perempuan didapatkan 15 anak berkemampuan baik dan 4 anak berkemampuan cukup, sedangkan dari 13 anak laki-laki 
didapatkan 5 anak berkemampuan baik dan 8 anak berkemampuan cukup.

Hasil penelitian tersebut sejalan dengan teori Gray (2013) dikutip Putri (2016) yang menjelaskan bahwa anak laki-laki mempunyai kemampuan pendengaran yang kurang efektif sehingga tidak dapat berbicara dan mendengarkan dalam waktu yang sama. Jenis kelamin sangat berpengaruh dalam kemampuan anak dalam mencuci tangan pakai sabun dengan benar. Anak perempuan lebih mudah dalam menerima materi yang disampaikan karena anak perempuan lebih fokus dan konsentrasi sehingga mampu menerapkan praktik cuci tangan pakai sabun sesuai langkah-langkah yang benar dibandingkan anak laki-laki.

Anak sekolah dasar merupakan periode emas dalam menanamkan pengetahuan dan perilaku hidup bersih dan sehat. Pada taraf ini anak sangat peka terhadap stimulus sehingga mudah dibimbing, diarahkan dan ditanamkan kebiasaan yang baik karena anak berasa ada masa pertumbuhan dan perkembangan (Ony, 2010). Oleh karena itu, pada taraf ini anak sangat tepat untuk ditanamkan kebiasaan yang baik salah satunya yaitu dengan cara memberikan pendidikan kesehatan. Selain itu pendidik juga perlu menggunakan media yang kreatif dan inovatif dalam memberikan pendidikan kesehatan. Salah satu media yang digunakan adalah media video. Media ini dianggap lebih tepat bagi anak-anak karena terkesan menghibur dan tidak membosankan. Media ini juga mampu melukiskan gambar hidup dan suara memberikan daya tarik tersendiri sehingga selain menjadi media hiburan juga dapat digunakan sebagai media edukasi yang mudah dipahami dari anak-anak hingga orang tua (Prastowo, 2012).

Menurut asumsi peneliti, bahwa pendidikan kesehatan cuci tangan pakai sabun dengan media video mampu membantu meningkatkan kemampuan cuci tangan pada anak sekolah. Penggunaan media video dalam pendidikan kesehatan menyebabkan responden menyerap pengetahuan lebih banyak karena melibatkan dua indera terbesar dalam penyerapan informasi, yaitu indera pengelihatan dan pendengaran. Peningkatan kemampuan cuci tangan dapat terjadi karena adanya penayangan video yang berisikan materi cuci tangan yang dibuat dalam bentuk adegan-adegan yang membuat terasa lebih nyata sehingga terjadi proses dalam belajar untuk menimbulkan perilaku yang positif dimana anak akan mengikuti apa yang ditayangkan pada video tersebut untuk kehidupan sehari-harinya. Faktor jenis kelamin juga memiliki pengaruh terhadap kemampuan cuci tangan karena pada anak perempuan dapat mendengarkan penjelasan dengan lebih baik dan teliti sehingga anak perempuan lebih mampu menerapkan yang telah diajarkan dibandingkan anak laki-laki.

\section{SIMPULAN}

Berdasarkan analisa data hasil penelitian pengaruh pendidikan kesehatan cuci tangan pakai sabun dengan media video terhadap kemampuan cuci tangan pada siswa kelas III SDN 1 Berangbang Jembrana, maka ditarik kesimpulan bahwa sebelum diberikan pendidikan kesehatan cuci tangan pakai sabun dengan media video, sebagian besar kemampuan cuci tangan dari 27 siswa (100\%) didapatkan 24 siswa $(88,9 \%)$ dengan kategori tidak mampu. Setelah diberikan pendidikan kesehatan cuci tangan pakai sabun dengan mdia video, sebagian besar kemampuan cuci tangan dari 27 siswa (100\%) didapatkan 25 siswa $(92,6 \%)$ dengan kategori mampu. Dari hasil uji statistik Wilcoxon Signed Rank Test, diketahui nilai $\mathrm{p}=0,000$ sehingga $\mathrm{p}<\alpha$ (nilai $\alpha=0,05$ ) 
maka $\mathrm{HO}$ ditolak dan Ha diterima sehingga ada pengaruh pendidikan kesehatan cuci tangan pakai sabun dengan media video terhadap kemampuan cuci tangan pada siswa kelas III SDN 1 Berangbang Jembrana.

Kepada pihak sekolah agar hasil penelitian ini bisa dijadikan bahan pertimbangan dan pedoman terkait masalah pelaksanaan UKS di sekolah agar dapat meningkatkan kesehatan siswa sehingga dapat meningkatkan pelaksanaan pendidikan kesehatan yang terkait dengan PHBS khususnya cuci tangan pakai sabun dengan media video serta menambahkan sarana dan prasarana untuk mencuci tangan seperti wastafel dan sabun agar pelaksanaan dapat berjalan optimal. Bagi tenaga Keperawatan Puskesmas khususnya perawat komunitas sebagai pemberi pelayanan agar dapat berperan aktif untuk meningkatkan kesehatan siswa dan mengoptimalkan program pendidikan kesehatan cuci tangan pakai sabun secara rutin kepada semua populasi yang ada di sekolah.

\section{DAFTAR PUSTAKA}

Andriani, V. D. (2017) 'Pengaruh Media Audio Visual Cuci Tangan Terhadap Kemampuan Cuci Tangan Pakai Sabun Anak Pra Sekolah (Di TK Cendana Murni Desa Cendono Kecamatan Padangan Bojonegoro)'. STIKES Insan Cendekia Medika Jombang.

Ardianto, H. S. and Khusnal, E. (2013)

'Pengaruh Pendidikan Kesehatan Dengan metode Audiovisual Terhadap Perilaku Cuci Tangan Pada Anak Pra Sekolah Di TK ABA Notoyudan Yogyakarta'. STIKES'Aisyiyah Yogyakarta.

Arsyad, A. (2011) 'Media Pembelajaran Berbasis Internet', Jurnal Media Pendidikan Agama.

Departemen Kesehatan (2011) Pedoman Manajerial Pencegahan dan
Pengendalian Infeksi Rumah Sakit dan Fasilitas Pelayanan Rumah Sakit dan fasilitas pelayanan Kesehatan Lainnya.

Dinas Kesehatan Kabupaten Jembrana. 2018. Profil Kesehatan Dasar Tahun 2018. Jembrana: Dinas Kesehatan

Dinas Kesehatan Provinsi Bali. 2016. Profil Kesehatan Provinsi Bali. Denpasar: Dinas Kesehatan

Kemenkes RI, P. R. (2014) Profil Kesehatan Indonesia Tahun 2013, Jakarta: Kementerian Kesehatan RI.

Kemenkes, R. (2015) Profil Kesehatan RI 2015, Profil Kesehatan Indonesia Tahun 2015. doi: 10.1111/evo.12990.

Kusbiantoro, D. (2015) 'Pemberian Health Education Meningkatkan Kemampuan Mencuci Tangan Pada Anak Prasekolah', Surya. doi: 10.1046/j.1365-2028.2000.00243.x.

Lufianti, A. (2010) 'Perbedaan Pengaruh Pembelajaran Perawatan Payudara (Breast Care) Dengan Video Compact Disc (Vcd) Dibanding Dengan Phantom terhadap Pengetahuan dan Motivasi Belajar (pada Mahasiswa D-III Keperawatan Sekolah Tinggi Ilmu Kesehatan An-Nur Purwodadi)'. UNS (Sebelas Maret University).

Ony, L. (2010) 'Praktik perilaku hidup bersih dan sehat (PHBS) pada peserta pendidikan anak usia dini (PAUD) di Kecamatan Koja, Jakarta Utara Tahun 2010', Universitas Muhamadiyah Prof. DR. Hamka.

Pramono, M. S. dkk. (2011) 'Pengembangan Permainan Multimedia Interaktif Tentang Perilaku Hidup Bersih Dan Sehat Pada Siswa Sekolah Dasar', Buletin Penelitian Kesehatan.

Prastowo, A. (2014) 'Panduan Kreatif Membuat Bahan Ajar Inovatif', PLoS Medicine. doi: 10.1016/j.burns

Putri, H. A. (2017) 'Perbedaan Pengaruh Media Pembelajaran Lagu Dan Slide Pada Praktik Mencuci Tangan 
Ditinjau Dari Jenis Kelamin', Jurnal Penelitian Ilmu Pendidikan. doi: 10.21831/jpipfip.v9i2.12910.

Saputri, A. A. and Suryati, S. (2019) 'Pengaruh Pendidikan Kesehatan Menggunakan Audio-Visual Terhadap Pengetahuan Cuci Tangan Pakai Sabun (Ctps) Pada Anak Kelas IV Di Mi Jamilurrahman Bantul', Medika Respati: Jurnal Ilmiah Kesehatan, 14(3), pp. 245-254.

Sasmitha, N. R., Auli Ilmi, A. and Huriati (2017) 'Peningkatan Pengetahuan tentang Cuci Tangan melalui Pendidikan Kesehatan dengan Media Audiovisual', Journal of Islamic Nursing.

Wati, N., Yuniar, N. and Paridah (2017) 'Pengaruh Intervensi Penayangan Video Terhadap Pengetahuan, Sikap Dan Tindakan Tentang Cuci Tangan Pakai Sabun Pada Siswa Sdn 10 Kabawo Tahun 2016', Jurnal Ilmiah Mahasiswa Kesehatan Masyarakat.

WHO (2013) 'Global action plan for the prevention and control of noncommunicable diseases 20132020.', World Health Organization. doi: 9789241506236. 